\title{
Announcement: The Irwin Oppenheim Award
}

We are pleased to announce the Irwin Oppenheim Award for best paper in Physical Review E by young investigators. This award honors the memory and celebrates the legacy of the founding editor of Physical Review E [1]. A charismatic leader, Irwin Oppenheim served as the editor of the journal from its inception in 1993 until 2002. He set high standards and attracted authors and papers from new fields. Under his editorship, the journal grew substantially and transitioned to online publishing. Using his stature and impeccable integrity, Irwin established Physical Review E as the premier journal in statistical, nonlinear, biological, and soft matter physics. The award was conceived by the late David Chandler, a former student and a long-time friend of Irwin, and is endowed by generous contributions from Irwin's family and friends along with his students, colleagues, and the Physical Review E community.

The Oppenheim Award will recognize outstanding contributions to physics by early career scientists who publish in Physical Review E. The annual award will consist of a \$3,000 stipend, a certificate citing the contributions of the recipients, a travel allowance to attend the APS March Meeting, and an invitation to speak at the conference.

The award will be granted once a year to the authors of a regular article or Rapid Communication published in Physical Review E. This recognition is restricted to researchers who were awarded a doctorate (Ph.D.) degree no earlier than 12 years from the date the paper was published, and all authors of the paper must meet this eligibility criterion. A committee consisting of members nominated by relevant units of the American Physical Society and a prior recipient will select the winner based solely on the scientific merit of the paper.

The inaugural prize will be awarded to a paper published during the time period January 1, 2017 - December 31,2017 , and information about how to nominate a paper for this award will be available soon. We look forward to bestowing the first award at the 2019 March meeting marking the 120th anniversary of the American Physical Society. This meeting will take place in the city of Boston where Irwin was born, raised, and lived nearly his entire life.

Eli Ben-Naim

Editor

Physical Review E

(2) Published 1 March 2018

DOI: 10.1103/PhysRevE.97.030001

[1] G. Sprouse and E. Ben-Naim, In Memory of Irwin Oppenheim, https://journals.aps.org/pre/edannounce/in-memory-of-irwin-oppenheim 